\title{
A misdiagnosed potentially dangerous shoulder injury
}

\section{P M Jarrett}

Answers on $p 360$.

$\Lambda^{40}$ 40 year old engineer presented with a history of chronic left upper limb fatigue and pallor upon limb abduction and intermittent dysphagia. These symptoms caused significant interference with his daily life and had started after a fall onto his left shoulder during a rugby tackle nine years previously. Following the original injury he had attended an accident and emergency department where it was noted that he had a swollen discoloured neck and left upper limb, paraesthesia in the left hand and forearm, and an inability to actively move his shoulder. Asymmetry was noted between the medial ends of his clavicles and he was tender over his medial left clavicle. Plain radiographs of

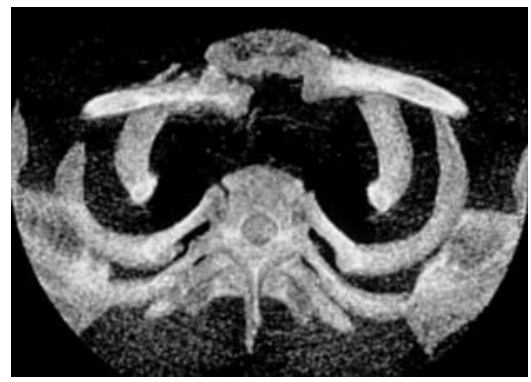

Figure 1 Three dimensional computed tomogram reconstruction of the thoracic outlet. his neck, chest, and shoulder after the injury were reported as normal. A diagnosis of muscle sprain and mild brachial plexus traction injury was made and he was observed in hospital for one day.

At representation nine years after the injury, examination revealed the medial aspect of his left clavicle to be less prominent than the right. Otherwise with his limbs resting by his side, his neck, shoulders, and upper limbs were normal to examination. On abduction the left upper limb gradually became white and after the limb was held abducted for one minute it became temporarily cyanosed upon returning it to the resting position. Neurological examination of his upper limbs was normal. His peripheral pulses were normal in the resting position but on the left were absent with the limb abducted. Computed tomography (fig 1 ) and arteriography with the limb in the resting (fig 2) and abducted positions (fig 3 ) were performed to aid in diagnosis.

\section{QUESTIONS}

(1) What is the diagnosis?

(2) What is demonstrated by arteriography?

(3) How should be injury have been managed upon initial presentation?

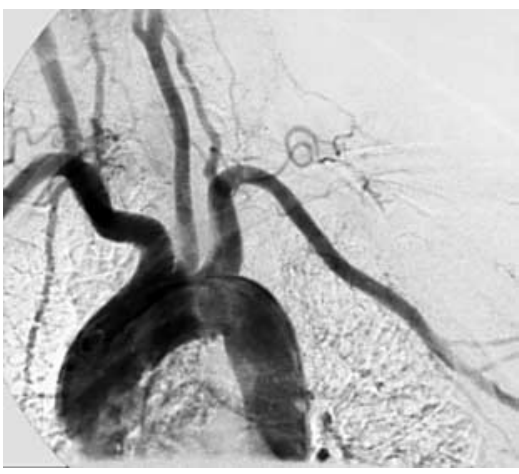

Figure 2 Arteriogram of his left subclavian artery with his arm in the resting position.

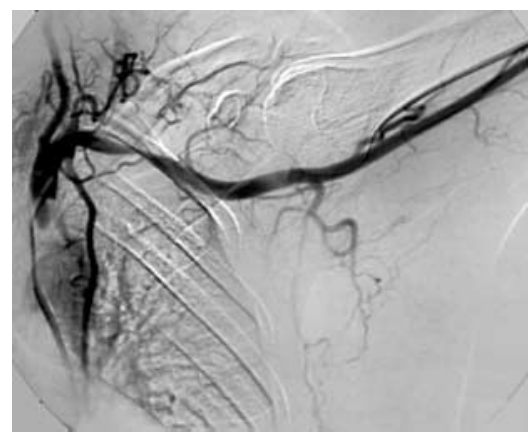

Figure 3 Arteriogram of his left subclavian artery with his arm in abduction.

(4) What are the management options nine years after injury?

Postgrad Med J 2003;79:357

\section{Authors' affiliations}

Correspondence to: Mr Paul M Jarrett, Department of Orthopaedic Surgery, Princess Alexandra Hospital, Harlow, Essex CM20 1QX UK; pmjarrett@rcsed.ac.uk

Submitted 25 September 2002

Accepted 9 December 2002

\section{A child with growth failure}

\section{S K Singh, A G Unnikrishnan, N K Agrawal, D Kapoor, A K Sahoo, D V S Reddy, R Kumar}

\section{Answers on $p 361$.}

A 7 year old girl presented with growth failure. She was born of a consanguineous marriage, and mental as well as motor milestones had been delayed. On examination her height was $93 \mathrm{~cm}$ (<3rd centile).
Nervous system evaluation revealed moderate mental retardation and a left lateral rectus palsy. The rest of the systemic examination was normal.

Investigations revealed a normal complete blood count. Serum biochemical reports were as follows: sodium 138 $\mathrm{mmol} / \mathrm{l}$, potassium $3.0 \mathrm{mmol} / \mathrm{l}$, bicarbonate $15.3 \mathrm{mmol} / \mathrm{l}$, chloride 138 $\mathrm{mmol} / \mathrm{l}$, total calcium $2.20 \mathrm{mmol} / \mathrm{l}$ (estimated value), phosphorous $1.1 \mathrm{mmol} / \mathrm{l}$, albumin $40 \mathrm{~g} / \mathrm{l}$, urea $5.1 \mathrm{mmol} / \mathrm{l}$, and creatinine $63 \mu \mathrm{mol} / \mathrm{l}$. Arterial blood pH was 7.22 and a corresponding urinary pH was 6.50; she did not have glycosuria. Computed tomography of the brain was done (fig 1). Serum acid phosphatase level was $10 \mathrm{U} / \mathrm{l}$ (normal range for age $0.11-0.6 \mathrm{U} / \mathrm{l})$. The alkaline phosphatase level was 228 IU/1 (normal $<450$ IU/l). Skeletal radiography including the skull, hand, spine and long bones was carried out, and the characteristic features are shown in fig 2. 


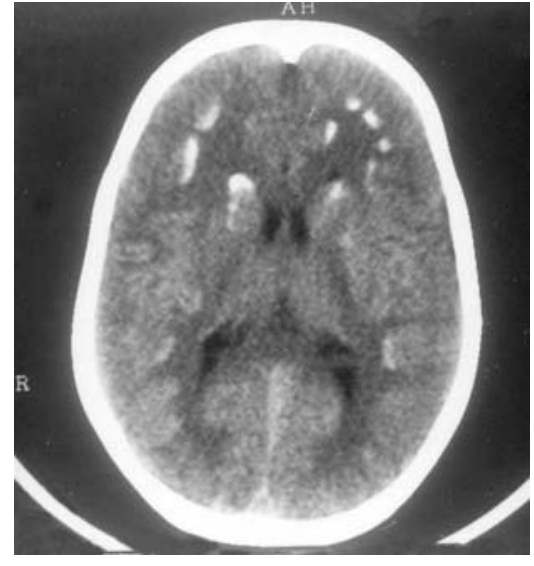

Figure 1 Computed tomogram of the brain.

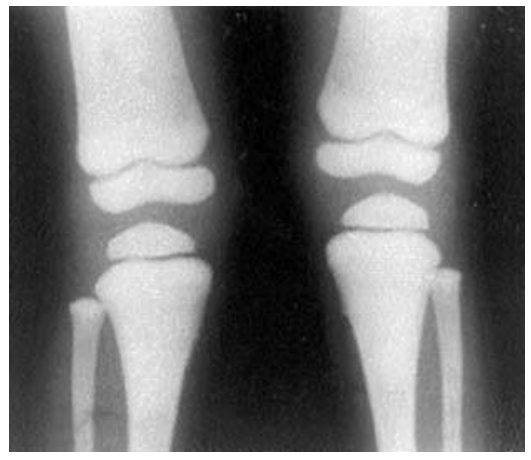

Figure 2 Radiograph of knee.

\section{QUESTIONS}

(1) What are the radiological and biochemical features, and the diagnosis of this case?

(2) What are the radiological features of this disorder?

(3) What are the treatment options and prognosis of this disorder?

Postgrad Med J 2003;79:357-358

\section{Authors' affiliations}

S K Singh, A G Unnikrishnan, N K Agrawal,

D Kapoor, A K Sahoo, D V S Reddy,

R Kumar, Department of Endocrinology and

Metabolism, Institute of Medical Sciences,

Banaras Hindu University, Varanasi 221005 ,

India

Correspondence to: Dr Singh;

suryakr1@satyam.net.in

Submitted 18 November 2002

Accepted 2 January 2003

Endocrinology

Magnetic resonance imaging (MRI) was done and the scans are shown in fig 1 .

\section{Multiorgan involvement in thalassaemia major}

\section{S Ghai, R Sharma, S Ghai, B Kulshreshtha}

\section{Answers on $p 361$.}

$\Lambda$ 16 year old girl with a history of $\beta$-thalassaemia major since birth was admitted as an emergency to hospital with a three day history of dyspnoea on exertion, facial puffiness, and carpopedal spasm. Physical examination revealed a thin, short girl with frontal bossing. The child was pale with greyish skin pigmentation, had not attained menarche, and there were no secondary sexual characteristics. There was an early systolic murmur along the left sternal border. Abdominal examination revealed hepatosplenomegaly.

\section{QUESTIONS}

(1) What are the findings on the MRI images?

(2) What is the diagnosis?

Postgrad Med J 2003;79:358

Authors' affiliations

Sangeet Ghai, Raju Sharma, Sandeep Ghai, Department of Radio-diagnosis, All India

Institute of Medical Sciences, New Delhi, India Bindu Kulshreshtha, Department of

Endocrinology

Correspondence and reprint requests to: $\mathrm{Dr}$ Sangeet Ghai; sangeet_ghai@yahoo.com

Submitted 17 June 2002

Accepted 10 September 2002
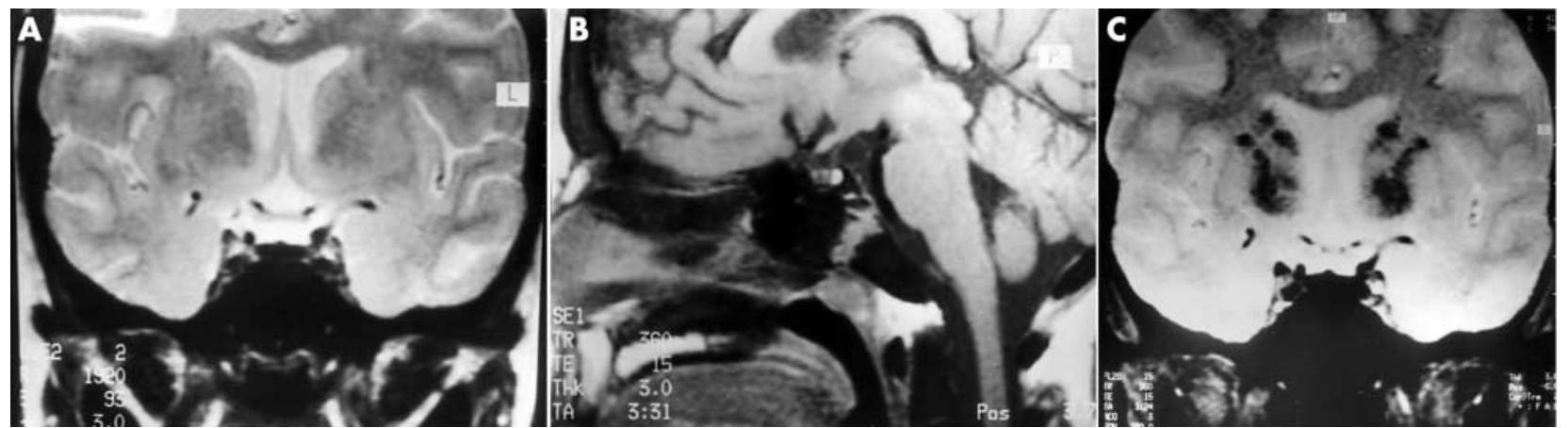

Figure 1 (A) Fast spin echo T2-weighted coronal MRI of the sella; (B) spin echo T1-weighted sagittal MRI of the sella; and (C) gradient echo T2-weighted coronal MRI. 